\title{
On the near-inertial variations of meridional overturning circulation in the South China Sea
}

\author{
Jingen Xiao ${ }^{1,2}$, Qiang Xie ${ }^{1,3}$, Dongxiao Wang ${ }^{1}$, Lei Yang ${ }^{1}$, Yeqiang Shu ${ }^{1}$, Changjian Liu ${ }^{4}$, Ju Chen $^{1}$, Jinglong Yao ${ }^{1}$, \\ and Gengxin Chen ${ }^{1}$ \\ ${ }^{1}$ State Key Laboratory of Tropical Oceanography (LTO), South China Sea Institute of Oceanology, \\ Chinese Academy of Sciences, Guangzhou, China \\ ${ }^{2}$ College of Earth Science, University of Chinese Academy of Sciences, Beijing, China \\ ${ }^{3}$ Sanya Institute of Deep-sea Science and Engineering, Chinese Academy of Sciences, Sanya, China \\ ${ }^{4}$ South China Sea Marine Engineering Survey Center, State Ocean Administration, Guangzhou, China
}

Correspondence to: Dongxiao Wang (dxwang@scsio.ac.cn)

Received: 21 July 2015 - Published in Ocean Sci. Discuss.: 10 September 2015

Revised: 4 January 2016 - Accepted: 2 February 2016 - Published: 1 March 2016

\begin{abstract}
We examine near-inertial variability of the meridional overturning circulation in the South China Sea (SCSMOC) using a global $1 / 12^{\circ}$ ocean reanalysis. Based on wavelet analysis and power spectrum, we suggest that deep SCSMOC has a significant near-inertial band. The maximum amplitude of the near-inertial signal in the SCSMOC is nearly $4 \mathrm{~Sv}$. The spatial structure of the signal features regularly alternating counterclockwise and clockwise overturning cells. It is also found that the near-inertial signal of SCSMOC mainly originates from the region near the Luzon Strait and propagates equatorward at a speed of $1-3 \mathrm{~m} \mathrm{~s}^{-1}$. Further analyses suggest that the near-inertial signal in the SCSMOC is triggered by high-frequency wind variability near the Luzon Strait, where geostrophic shear always exists due to Kuroshio intrusion.
\end{abstract}

\section{Introduction}

Near-inertial internal waves have been considered to be an important energy source for the diapycnal mixing in the ocean required to maintain the meridional overturning circulation (MOC; Munk and Wunsch, 1998). Previous studies show that the South China Sea (SCS) acts as a mixing mill that mixes the surface and deep waters and returns the mixed waters out of the Luzon Strait at an intermediate depth (Yuan, 2002; Tian et al., 2009; Yang et al., 2013, 2014).
The widest and deepest channel in the SCS is the Luzon Strait, which has a sill depth of about $2400 \mathrm{~m}$ and is the main passage connecting the SCS and the western North Pacific Ocean (Qu et al., 2006). Based on field observations, studies confirm the hypothesis that the Luzon Strait transport (LST) has a sandwiched vertical structure, which shows a westward flow in the upper layer $(<500 \mathrm{~m})$ and in the deeper layer $(>1500 \mathrm{~m})$, and an eastward flow in the intermediate layer (500-1500 m; Tian et al., 2006; Yang et al., 2010). The corresponding circulation in the SCS is consistent with the potential vorticity constraint (Yang and Price, 2000, 2007), which suggests that the mixing-induced circulation inside the SCS should be cyclonic gyres at the surface and at the bottom (Chao et al., 1996; Li and Qu, 2006; Wang et al., 2011; Lan et al., 2013; Xu and Oey, 2014), and an anti-cyclonic gyre at an intermediate depth (Isobe and Namba, 2001; Yuan, 2002). Note that the upper-layer SCS circulation is also affected by the seasonally reversing monsoon, exhibiting a cyclonic circulation over the whole SCS basin in winter, and in summer a strong anti-cyclonic circulation in the southern SCS and a weak cyclonic circulation in the northern SCS (Wrytki, 1961; Chu et al., 1999; Chu and Li, 2000; Qu, 2000; Hu et al., 2000; Liu et al., 2001; Wang et al., 2003; Su, 2004).

In the context of the strong mixing in the SCS and the sandwiched vertical structure of the Luzon Strait transport, Wang et al. (2004) proposed that the shallow meridional overturning in the SCS (SCSMOC) is semi-enclosed, transporting waters from north to south at a depth of about $500 \mathrm{~m}$ 
(a)

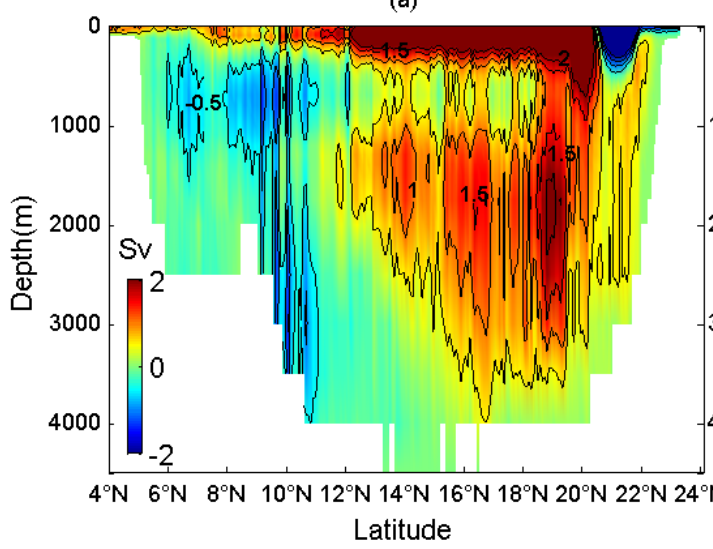

(b)

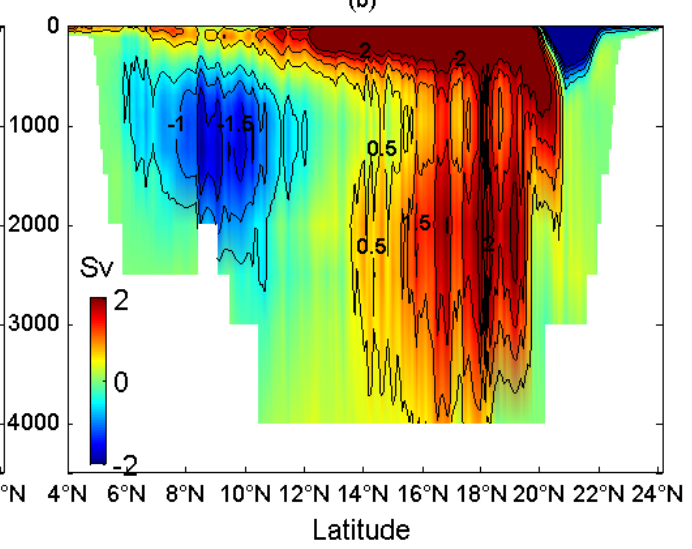

Figure 1. SCSMOC averaged from 2004 to 2010 based on GLBa0.08 (a) and GLBu0.08 (b).

(a)

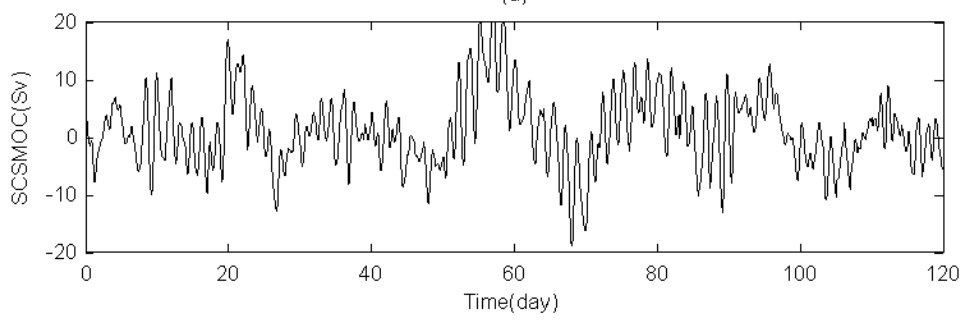

(b)

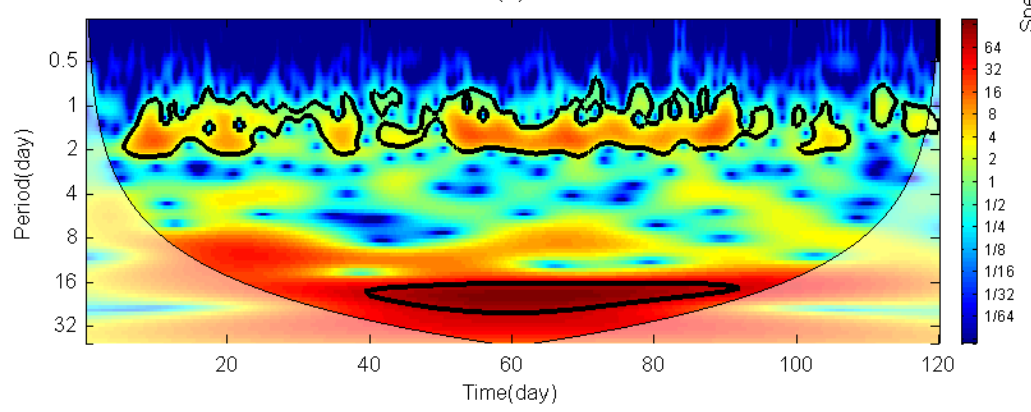

(c)

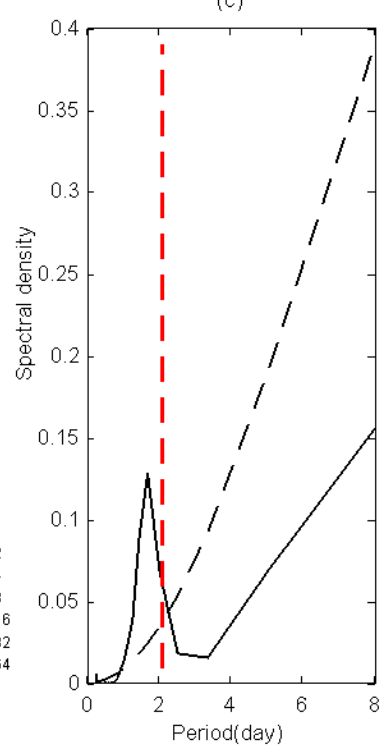

Figure 2. (a) Time series of SCSMOC at $1500 \mathrm{~m}, 14^{\circ} \mathrm{N}$; (b) the continuous wavelet power spectrum (black contours representing $95 \%$ significance); (c) the power spectrum (the dashed black line and red line show $95 \%$ confidence levels and the local inertial period, respectively).

(200 $\mathrm{m})$ and returning waters to the north at surface in winter (summer). The shallow SCSMOC hints at a transport path such that intermediate water enters the SCS from the western North Pacific Ocean (Wang et al., 2004; Xie et al., 2013). Zhang et al. (2014) further show that the shallow SCSMOC consists of downwelling in the northern SCS, a southward subsurface branch supplying upwelling in the southern SCS, and a northward return flow of surface water. Based on the high-resolution global reanalysis data (GLBa0.08), Shu et al. (2014) found that the whole SCSMOC also has a sandwiched structure driven by the Luzon Strait transport, consisting of a stronger semi-enclosed clockwise overturning circulation in the upper layer, a weaker counterclock- wise overturning circulation in the intermediate layer, and a weaker clockwise overturning circulation in the deep layer.

The SCSMOC variability spans a wide range of timescales. On a decadal timescale, the intermediate water of the SCS was fresher in the 1980s than that in the 1960s, caused by the deep SCSMOC decreasing from the 1960s to the 1980s according to an ocean reanalysis (Liu et al., 2012). On the interannual scale, the Luzon Strait transport shows a remarkable interannual variability associated with El Niño-Southern Oscillation (ENSO, Qu et al., 2004). The upper LST correlates with the local wind stress, while the lower LST shows a statistically significant correlation with the Nino3.4 index (Qu et al., 2005; D. Wang et al., 2006; Y. Wang et al., 2006), indicating that the shallow SCSMOC 


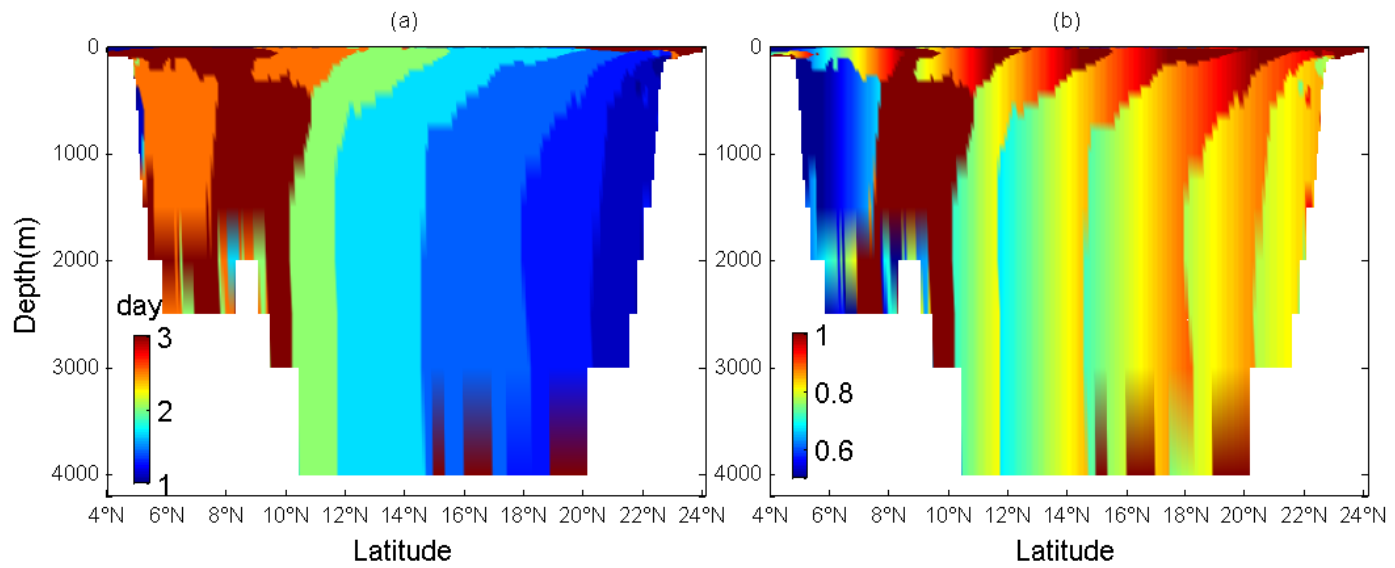

Figure 3. (a) The period corresponding to the power peak of the SCSMOC, which passes $95 \%$ significance; (b) the ratio of the peak period of the SCSMOC to the local inertial period.

also has an interannual variability related to ENSO. On a seasonal scale, the seasonal variability of the shallow SCSMOC mostly controls the strength of seasonal intrusions of the North Pacific Water into the SCS (Liu et al., 2008). Moreover, the deep overflow through the Luzon Strait is strong in summer but weak in winter, driving the seasonal variability of the deep SCSMOC (Lan et al., 2015).

The existence of near-inertial (several days) variability of the Atlantic meridional overturning circulation (AMOC) has been recently reported by using a high-resolution oceanic general circulation model (Blaker et al., 2012). This variability is associated with equatorward-propagating near-inertial gravity waves (NIGWs). However, there is no study so far for shorter-timescale variability (especially for near-inertial variation) of the SCSMOC. In this paper, we examine the near-inertial variations of the SCSMOC and identify the generation processes behind the variations using a realistic highresolution ocean reanalysis. The rest of the paper is organized as follows. The data and methods are introduced in Sect. 2 . The results are presented in Sect. 3. Sections 4 and 5 give a discussion and conclusion.

\section{Data and method}

The product of the Hybrid Coordinate Ocean Model+Navy Coupled Ocean Data Assimilation (HYCOM+NCODA) global $1 / 12^{\circ}$ reanalysis (GLBu0.08, http://hycom.org/ dataserver/glb-reanalysis) provided by the Naval Research Laboratory is used in this study. As a dynamical model, HYCOM 2.2 is configured for the global ocean with the bathymetry derived from the 30 arcsec GEBCO (General Bathymetric Chart of the Oceans) data set. The K-Profile Parameterization (KPP) mixing scheme is adopted for the vertical diffusion of momentum, temperature, and salinity (Thoppil et al., 2011). The model is forced by the hourly wind stress and heat fluxes derived from National Centers for
Environmental Prediction (NCEP) Climate Forecast System Reanalysis (CFSR) with horizontal resolution of $0.3125^{\circ}$. Note that there is no tidal forcing during the integration. It is initialized using temperature and salinity from the $1 / 4^{\circ}$ Generalized Digital Environmental Model (GDEM4) climatology in January. The NCODA assimilates available satellite altimeter observations; satellite and in situ sea surface temperature (SST); and available in situ vertical temperature and salinity profiles from expendable bathythermographs (XBTs), Argo floats, and moored buoys using a 3-D variational scheme (Cummings, 2005). The model output is stored every $3 \mathrm{~h}$.

Based on the equation of continuity, the meridional overturning stream function can be defined as (Endoh and Hibiya, 2007)

$$
\begin{aligned}
& \frac{\partial \psi(y, z, t)}{\partial z}=-\int_{x_{\mathrm{W}}}^{x_{\mathrm{e}}} v(x, y, z, t) \mathrm{d} x, \\
& \frac{\partial \psi(y, z, t)}{\partial y}=\int_{x_{\mathrm{W}}}^{x_{\mathrm{e}}} w(x, y, z, t) \mathrm{d} x .
\end{aligned}
$$

Because there is no vertical velocity $(w)$ provided in GLBu0.08, the meridional overturning stream function in SCS could be calculated as

$\psi(y, z, t)=-\int_{-H}^{z} \mathrm{~d} z \int_{x_{\mathrm{w}}}^{x_{\mathrm{e}}} v(x, y, z, t) \mathrm{d} x$,

where $x_{\mathrm{w}}$ and $x_{\mathrm{e}}$ are the western and eastern limits of the basin, respectively, and $H$ is the ocean bottom. Although the meridional overturning stream function is calculated only by the meridional velocity $(v)$, it also represents the integrated vertical motions in the basin because of the equation of continuity (Endoh et al., 2007). Shu et al. (2014) have used another product of $\mathrm{HYCOM}+\mathrm{NCODA}$ global $1 / 12^{\circ}$ reanalysis 

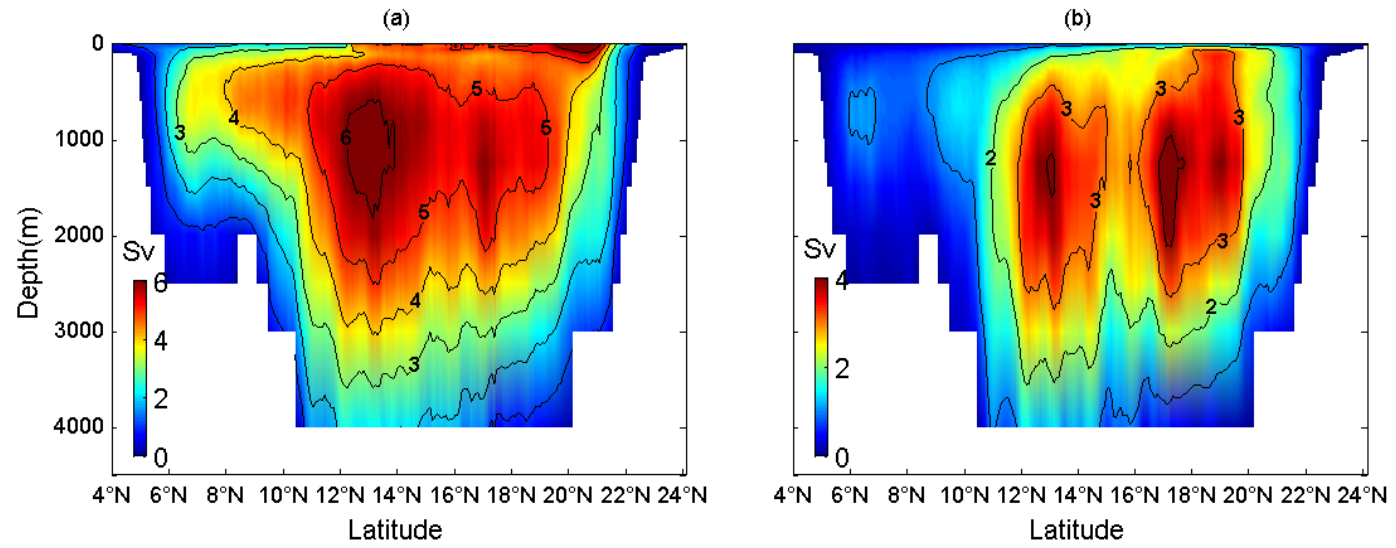

Figure 4. (a) The standard deviations of the SCSMOC in 2010 and (b) the filtered 1-3-day SCSMOC signal in 2010.
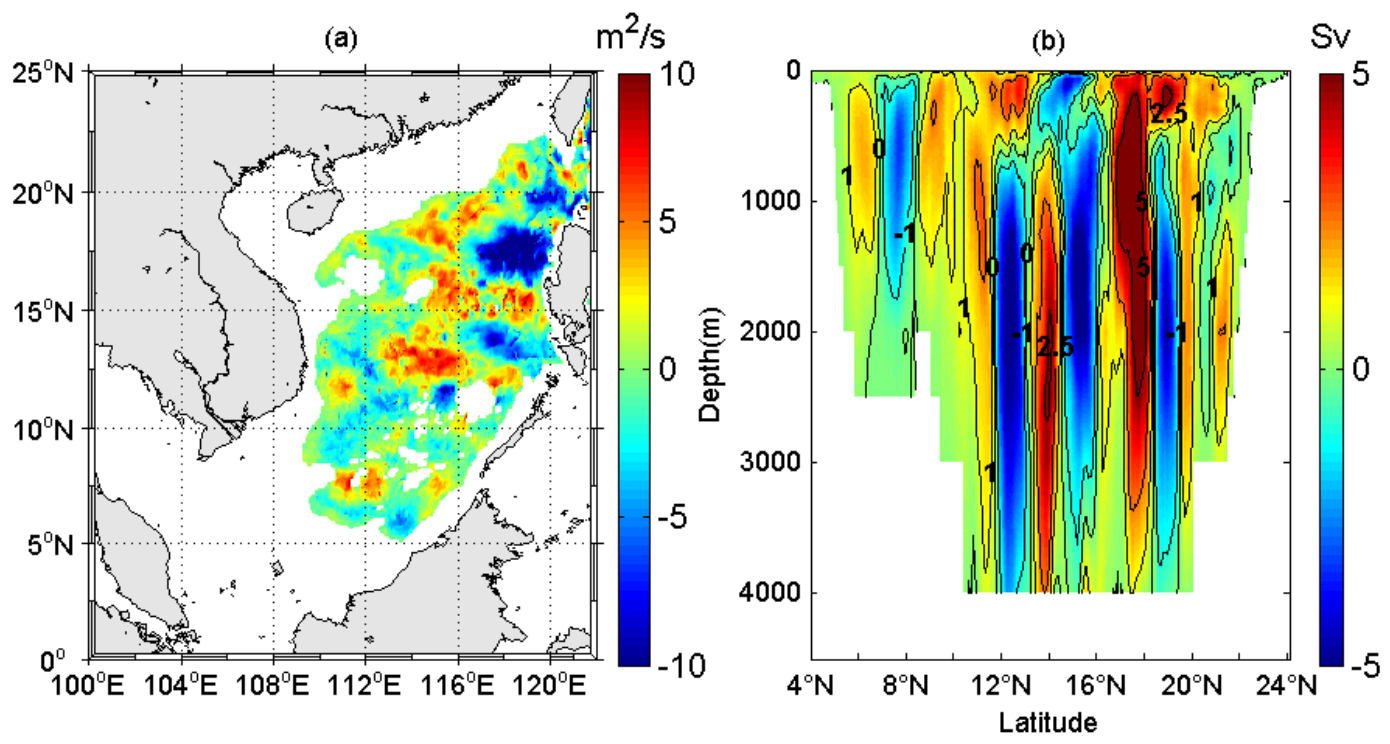

Figure 5. The snapshot of (a) the integrated meridional velocity field from the bottom to $1000 \mathrm{~m}$ and (b) the filtered SCSMOC signal at 24:00 GMT in January 2010.

(GLBa0.08, Fig. 1a) to depict the structure of the SCSMOC. The only difference between GLBa0.08 and GLBu0.08 is the external forcing field. GLBa0.08 is forced by Navy Operational Global Atmospheric Prediction System (NOGAPS), while GLBu0.08 is driven by the Climate Forecast System Reanalysis (CFSR). Figure 1 shows the SCS meridional overturning stream function averaged from 2004 to 2010 based on GLBa0.08 and GLBu0.08. It is found that the two products show a roughly similar SCSMOC, which consists of a semi-enclosed clockwise upper overturning cell, a counterclockwise intermediate overturning cell, and a clockwise deep overturning cell as shown in Fig. 1. The main difference is that the intermediate cell in GLBu0.08 is stronger, the deep cell stretches less southward compared with the GLBa0.08, and the upper cell in GLBu0.08 is deeper. More importantly, compared with the daily-output GLBa0.08, GLBu0.08 has a
$3 \mathrm{~h}$ output, which is better for studying motion with periods of only a couple of days. So the GLBu0.08 product in 2010 is chosen to analyze the characteristics of near-inertial variability of the SCSMOC in this study.

\section{Characteristics of the near-inertial variability of the SCSMOC}

Figure 2a shows the 120-day time series of the deep SCSMOC (at $1500 \mathrm{~m}$ and $14^{\circ} \mathrm{N}$ ) from 1 January 2010. It is found that the SCSMOC experiences an obvious intra-seasonal variability superimposed with persistent highfrequency undulations (Fig. 2a). The wavelet analysis shows that the high-frequency undulations correspond to strong and persistent power on the band of 1-3 days while the intraseasonal variability has power with periods of about 16-32 
(a)

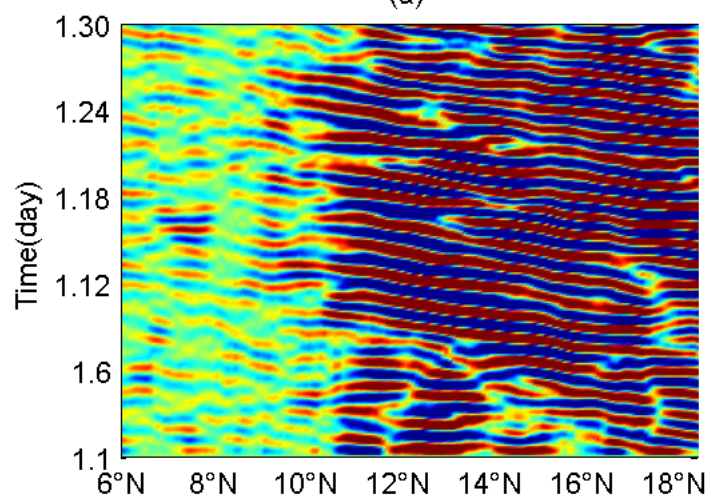

(c)

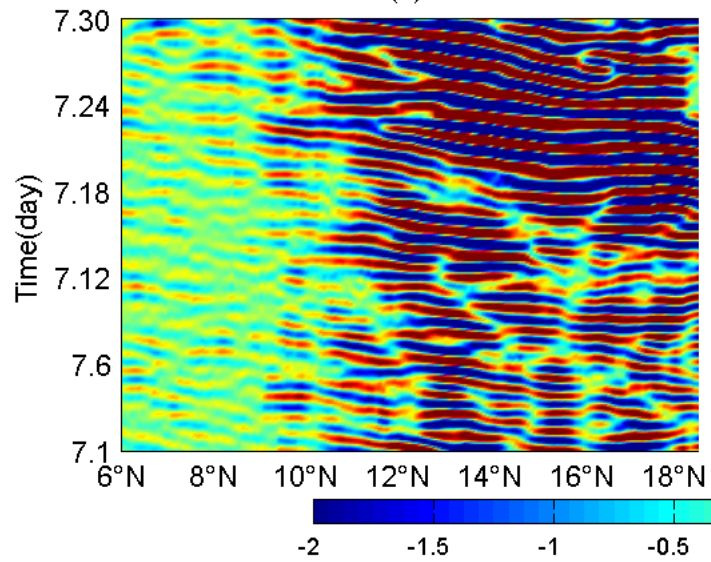

(b)

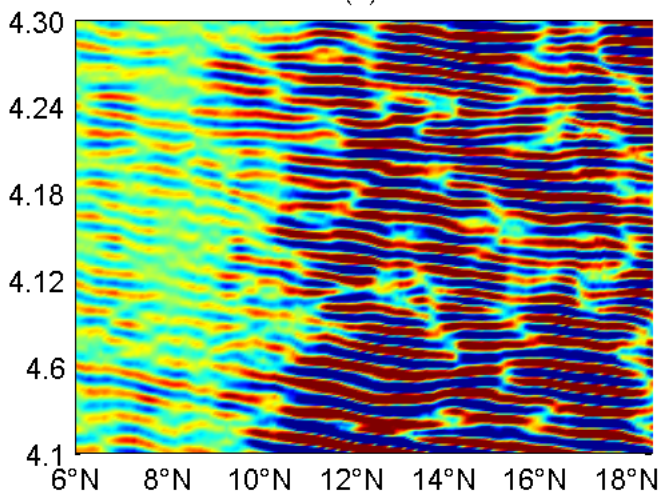

(d)

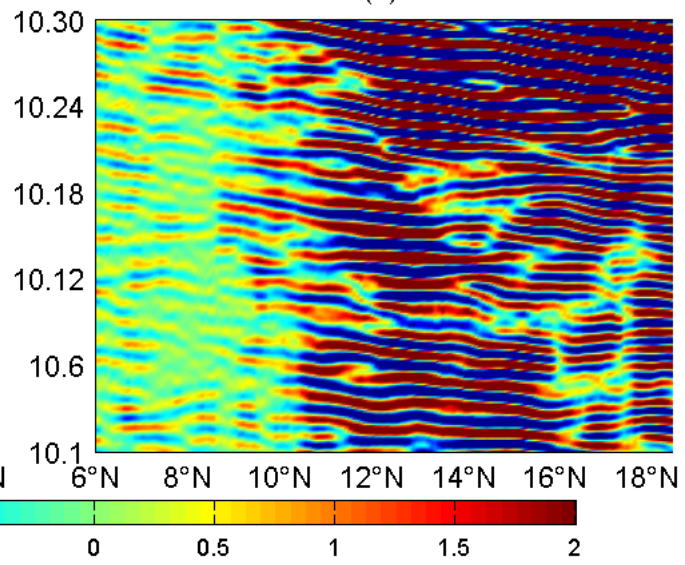

Figure 6. Time-latitude plot of 1-3-day band-passed SCSMOC signal at $1500 \mathrm{~m}$ in (a) January, (b) April, (c) July, and (d) October in 2010.

days (Fig. 2b). The spectral analysis further confirms that there is an obvious period band of 1-3 days in the deep SCSMOC time series (Fig. 2c). It is also found that the period corresponding to the power peak of SCSMOC is prolonged equatorward from 1 day at $20^{\circ} \mathrm{N}$ to 3 days at $10^{\circ} \mathrm{N}$ (Fig. 3a). It is noted that the near-inertial band in the SCS is from 1.46 days at $20^{\circ} \mathrm{N}$ to 3.59 days at $10^{\circ} \mathrm{N}$ (Chen et al, 2014). Comparing with the local inertial period in the SCS, the deep SCSMOC is at super-inertial frequencies (the frequency corresponding to the power peak is larger than the local inertial frequency), while the shallow SCSMOC is at inertial frequencies. However, the SCSMOC between 8 and $10^{\circ} \mathrm{N}$ is at sub-inertial frequencies (the frequency corresponding to the power peak is less than the local inertial frequency). Our results also show that these near-inertial variations of the SCSMOC exist in other seasons and other years (not shown). The near-inertial variations of the SCSMOC also have a strong seasonality. The analysis of other months or years cannot change our conclusion significantly, so we just use the 2010 data to depict the near-inertial variations of the SCSMOC.

To extract the near-inertial signal of the SCSMOC, a thirdorder Butterworth filter is applied to the time series of the
SCSMOC at each latitude and depth. Cutoff frequencies are set at $[0.33,1] \mathrm{cpd}$, which correspond to the 1-3-day band. The maximum standard deviation (SD) of the filtered SCSMOC signal is nearly $4 \mathrm{~Sv}$ (Fig. 4b), nearly half of the maximum SD of total SCSMOC in 2010 (Fig. 4a). The largest amplitude of the near-inertial signal in SCSMOC is found in the mid-layer $(500-2500 \mathrm{~m})$. There are two high SDs at the mid-depth (500-2500 m): the northern one is between 16 and $20^{\circ} \mathrm{N}$, and the southern one between 12 and $14^{\circ} \mathrm{N}$ (Fig. 4b). Near the Luzon Strait (around $19^{\circ} \mathrm{N}$ in Fig. 4b) there exists a maximum of the shallow SCSMOC variability in the layer (100-500 m).

Based on the snapshot of the integrated filtered meridional velocity field from the bottom to $1000 \mathrm{~m}$ at 24:00 GMT on 15 January 2010 (Fig. 5a), it is obvious that the integrated velocity field consists of regularly alternating positive and negative bands. Furthermore, Fig. $5 b$ is the snapshot of the filtered SCSMOC signal at the same time as in Fig. 5a. The spatial structure of the near-inertial signal is stacked with regularly alternating positive and negative cells. The maximum amplitude of these cells is nearly $5 \mathrm{~Sv}$, and most of the cells are concentrated in the depth between 1000 to $2500 \mathrm{~m}$ and within the latitude between 10 and $20^{\circ} \mathrm{N}$, while the cells are 
(a)

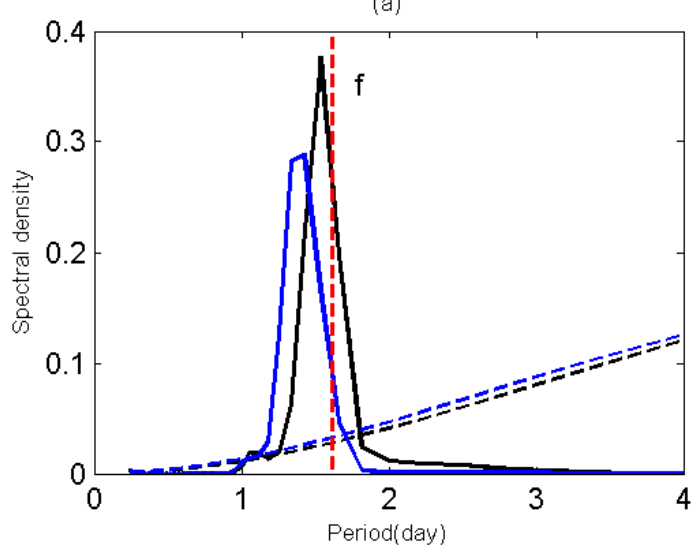

(b)

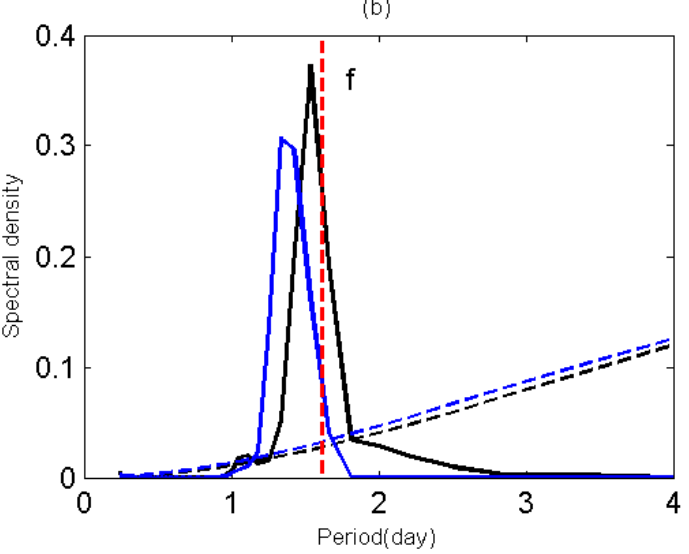

Figure 7. The power spectrum of zonal velocity (a) and meridional velocity (b) derived from the mooring (black line) and GLBu0.08 (blue line). The dashed black and blue line shows $95 \%$ confidence levels, while the dashed red line represents the local inertial period. The tide effects have been removed in the mooring data.

not so evident in the upper layer. These cells are stretched not in the meridional direction but in the vertical direction, which means each cell consists of both the strong upwelling branch and the downwelling branch. The regularly alternating positive and negative bands in the meridional direction imply a characteristic wavelength of $\sim 150-200 \mathrm{~km}$, while the vertical coherent structure suggests that these cells are dominated by the first baroclinic mode, which is consistent with the near-inertial variations of AMOC (Blaker et al., 2012; Sévellec et al., 2013). From 4 to $10^{\circ} \mathrm{N}$ and 20 to $22^{\circ} \mathrm{N}$, there are also weak cells. Upwelling and downwelling at the middepths are also found in the open ocean, like the Atlantic and Pacific Ocean, based on the high-resolution model simulations where the vertical velocity was used to diagnose the deep-ocean near-inertial gravity waves (Komori et al., 2008; von Storch, 2010). The pattern of the near-inertial variability of SCSMOC (Fig. 4b) is very similar to the near-inertial variability of the Atlantic Ocean (Komori et al., 2008; Blaker et al., 2012; Sévellec et al., 2013). The imprint of NIGWs in AMOC is also stacked with regularly alternating positive and negative cells between 10 and $4^{\circ} \mathrm{N}$, which span 500 to $4000 \mathrm{~m}$ (Blaker et al., 2012; Sévellec et al., 2013). The power peak of AMOC is at super-inertial frequencies, which is similar to that of the SCSMOC.

To investigate the meridional propagation of near-inertial signals in the SCSMOC at mid-depths (500-2500 m), Fig. 6 shows the meridional structure of the filtered near-inertial signal at $1500 \mathrm{~m}$ in four typical months (January, April, July, and October) in 2010. It is found that most of the signal propagates southwards from the region near Luzon Strait (where $18^{\circ} \mathrm{N}$ is the latitude of the southern tip of the Luzon Strait in Fig. 6) regardless of the different months. The propagating velocity is about $1-3 \mathrm{~m} \mathrm{~s}^{-1}$. It was noted that the NIGWs usually have the dominant frequency of $\mathrm{f}$ (Coriolis frequency) and usually propagate equatorward due to beta dispersion (Anderson and Gill, 1979; Garrett, 2001). The meridional propagation of the filtered SCSMOC signal and near-inertial period (Fig. 3b) indicate that the striped pattern of the filtered 1-3-day SCSMOC signal represents ocean NIGWs formed especially near the Luzon Strait and propagating equatorward.

\section{Discussion}

The East Asian monsoon system prevails over the SCS, which is frequently affected by strong tropical cyclones (TCs) originating from the western Pacific (Zheng et al., 2015). Strong vertical mixing and horizontal pressure gradients caused by typhoon winds can lead to the formation of strong NIGWs in the ocean interior (Garrett, 2001). Previous observations of NIGWs are focused on the upper layer in the SCS (Liang et al., 2005; Xie et al., 2009; Xu et al., 2013; Chen et al., 2013); only Yuan et al. (2002) have found there to be strong NIGWs below $1800 \mathrm{~m}$ in the northeastern SCS using two current meters. A mooring was located at $114.57^{\circ} \mathrm{E}$, $17.99^{\circ} \mathrm{N}$, where the water depth is about $3500 \mathrm{~m}$. An Aanderaa current meter was positioned at $300 \mathrm{~m}$ above the bottom, and the valid current meter data were collected from 21 March 2006 to 19 September 2006 with a sampling interval of $1 \mathrm{~h}$. The 120-day data beginning 1 April 2006 were used in this study. The power spectrum of zonal velocity and meridional velocity in the mooring data and model output peak near the inertial frequency (Fig. 7).

Near-inertial variability in the ocean is mainly caused by wind variability through a resonant response of ocean currents to wind (Gill, 1984). The imprint of NIGWs on AMOC has been found mostly related to wintertime storm tracks (Blaker et al., 2012; Sévellec et al., 2013; Furuichi et al., 2008; Rimac et al., 2013), while the imprint of NIGWs on SCSMOC might be related to wind variability near the Luzon 
(a)

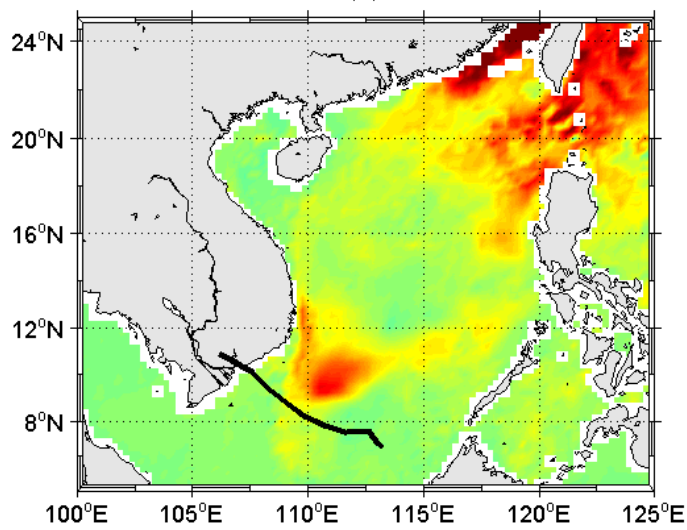

(c)

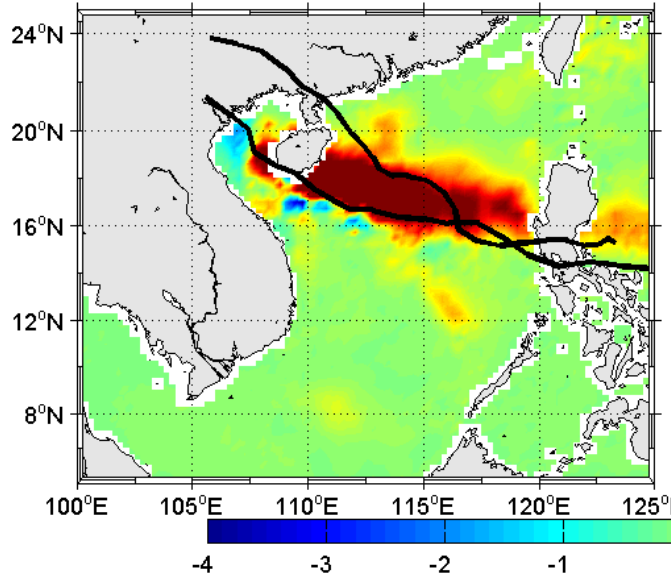

(b)

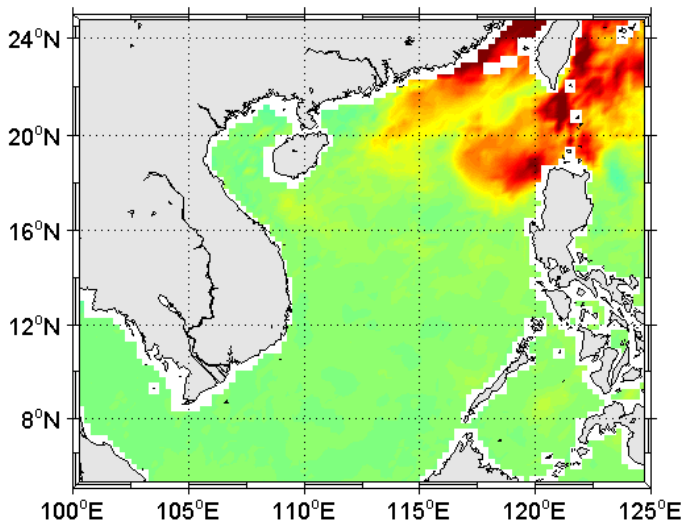

(d)

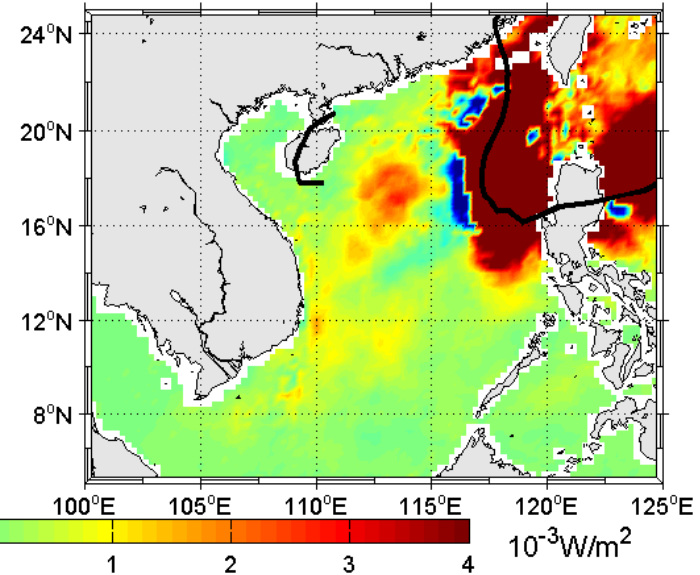

Figure 8. Spatial distribution of the monthly mean near-inertial energy input by wind in (a) January, (b) April, (c) July, and (d) October in 2010. The black line is the best track of TC derived from the Joint Typhoon Warning Center (JTWC).

Strait (Li et al., 2015). Figure 8 further shows the monthly mean near-inertial energy input by wind during four representative months (January, April, July, and October) in 2010. It is found that wind-induced near-inertial energy input is always strong west of the Luzon Strait. In spring, autumn, and winter, these strong high-frequency wind wakes in the Luzon Strait could drive the NIGWs near the Luzon Strait (Fig. 8a$\mathrm{b}$ and d). An average of about seven TCs pass through the Luzon Strait from the western North Pacific Ocean each year (Wang et al., 2007; Zheng et al., 2015); in particular, there were two TCs on July 2010 and one TC on October 2010 passing through the region to the west of the Luzon Strait, inducing strong wind-induced near-inertial energy input into the ocean (Fig. 8c), so TCs could also be drivers of the NIGWs near the Luzon Strait. The horizontal distribution of large integrated near-inertial kinetic energy roughly corresponds to that of the strong wind-induced near-inertial energy input (Figs. 8 and 9). In addition, due to beta dispersion of the NIGWs (Anderson and Gill, 1979; Garrett, 2001; Chriswell, 2003), the region of the integrated near-inertial kinetic energy is stretched equatorward. Furthermore, an in- tense density front usually exists in the Luzon Strait due to the Kuroshio (Wang et al., 2001), inducing positive vorticity west of the Kuroshio and negative vorticity to its east. On the one hand, the disturbance of the front (Kuroshio) can drive NIGWs through geostrophic adjustment (Kunze, 1985; Wang et al., 2009; Whitt and Thomas, 2013). On the other hand, the transfer of near-inertial energy to the deep ocean can be enhanced by the negative vorticity field (Lee and Niiler, 1998; Zhai et al., 2005). As the NIGWs leave the density front, they propagate equatorward due to beta dispersion (Anderson and Gill, 1979; Garrett, 2001; Chriswell, 2003). Therefore, strong NIGWs near the Luzon Strait can be detected in the deep SCSMOC south of the Luzon Strait as far as $10^{\circ} \mathrm{N}$. Although the Kuroshio intrusion is a low-frequency process, it can provide the background vorticity field for the vertical propagation through the chimney effect (Lee and Niiler, 1998; Zhai et al., 2005) because negative vorticity west of the Kuroshio near the Luzon Strait always exists. When the Kuroshio intrusion changes states among the looping path, the leaking path, and the leaping path (Nan et al., 2014), the geostrophic adjustment also triggers near-inertial waves. 
(a)

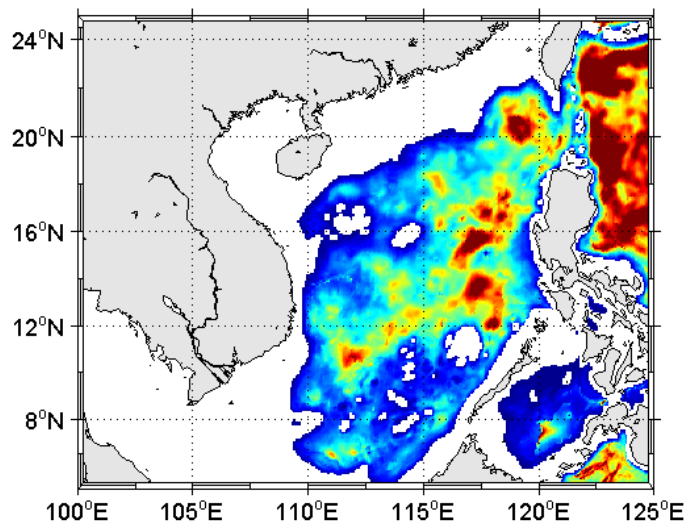

(c)

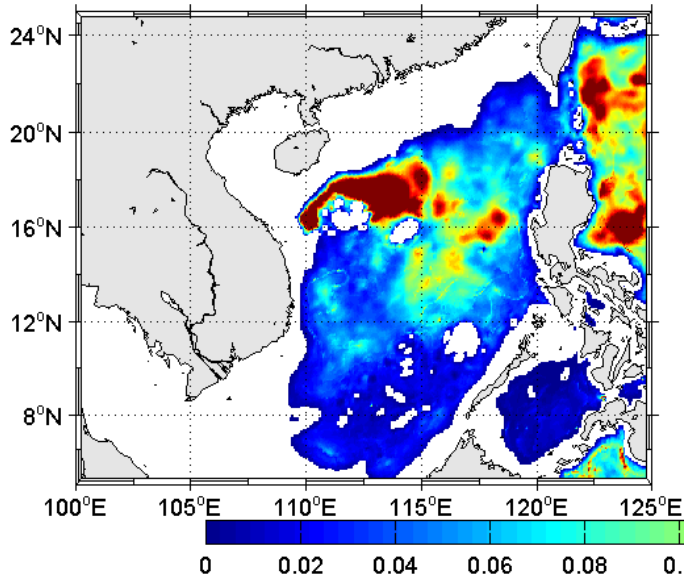

(b)

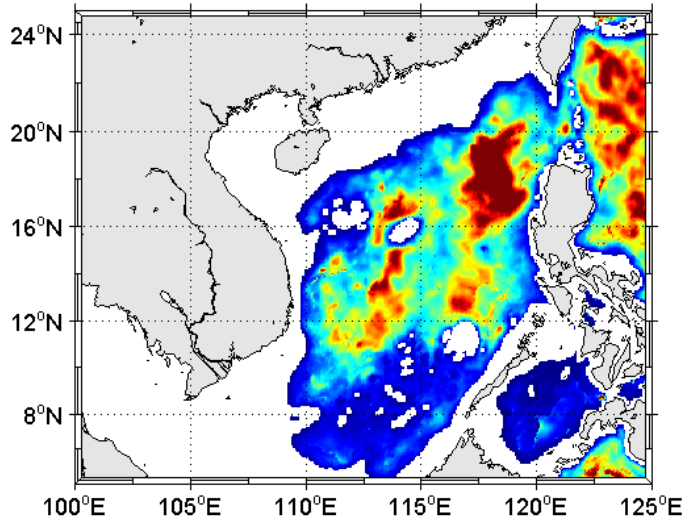

(d)

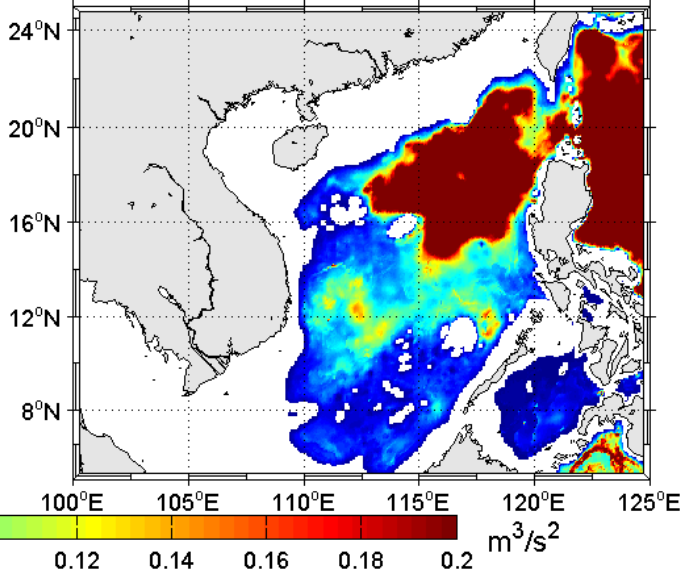

Figure 9. The monthly mean integrated near-inertial kinetic energy from the bottom to $1000 \mathrm{~m}$ in (a) January, (b) April, (c) July, and (d) October in 2010 .

This process is well depicted by Nagai et al. (2015) in relation to the Kuroshio meander. The question of the relative importance of high-frequency wind and Kuroshio intrusion on the near-inertial variations of SCSMOC needs more observational and modeling work in a future study.

\section{Conclusions}

A high-resolution ocean reanalysis (GLBu0.08) is used to reveal characteristics of the near-inertial variability in the deep SCSMOC. It is shown that there is an obvious high power peak on the near-inertial band in the deep SCSMOC time series. The maximum amplitude of the near-inertial signal in the SCSMOC is nearly $4 \mathrm{~Sv}$, and its largest amplitude appears in the middle layer $(500-2500 \mathrm{~m})$. The near-inertial signal in the SCSMOC propagates equatorward at a speed of 1$3 \mathrm{~m} \mathrm{~s}^{-1}$ from the region near the Luzon Strait. The imprint of NIGWs on the SCSMOC highlights the possible importance of NIGWs in the horizontal and vertical redistribution of wind energy throughout the SCS. Although the effect of these NIGWs at depth on turbulent mixing is still unknown, it is speculated that the breaking of these deep-ocean NIGWs could be a candidate for the enhanced mixing in the SCS.

Acknowledgements. This work was supported by the Strategic Priority Research Program of the Chinese Academy of Sciences (XDB06020102), the National Basic Research Program of China (91228202, 41276024, and 41476011), the Knowledge Innovation Engineering Frontier Project of the Sanya Institute of Deep Sea Science and Engineering (SIDSSE-201205), and the Sanya and Chinese Academy of Sciences Cooperation Project (2012YD01).

Edited by: J. M. Huthnance

\section{References}

Anderson, D. L. T. and Gill, A. E.: Beta dispersion of inertial waves, J. Geophys. Res.-Oceans, 84, 1836-1842, 1979.

Blaker, A. T., Hirschi, J. J. M., Sinha, B., de Cuevas, B., Alderson, S., Coward, A., and Madec, G.: Large near-inertial oscillations of the Atlantic meridional overturning circulation, Ocean Model., 42, 50-56, 2012. 
Chao, S. Y., Shaw, P. T., and Wu, S. Y.: Deep water ventilation in the South China Sea, Deep-Sea Res. Pt. I, 43, 445-466, 1996.

Chen, G., Xue, H., Wang, D., and Xie, Q.: Observed near-inertial kinetic energy in the northwestern South China Sea, J. Geophys. Res.-Oceans, 118, 4965-4977, doi:10.1002/jgrc.20371, 2013.

Chiswell, S. M.: Deep equatorward propagation of inertial oscillations, Geophys. Res. Lett., 30, 1533, doi:10.1029/2003GL017057, 2003.

Chu, P. C. and Li, R.: South China Sea isopycnal-surface circulation, J. Phys. Oceanogr., 30, 2419-2438, 2000.

Chu, P. C., Edmons, N. L., and Fan, C. W.: Dynamical mechanisms for the South China Sea seasonal circulation and thermohaline variabilities, J. Phys. Oceanogr., 29, 2971-2989, 1999.

Cummings, J. A.: Operational multivariate ocean data assimilation, Q. J. Roy. Meteor. Soc., 131, 3583-3604, 2005.

Endoh, T. and Hibiya, T.: Meridional overturning circulation of the deep Pacific estimated assuming the vertical advective-diffusive balance, Geophys. Res. Lett., 34, L11602, doi:10.1029/2007GL030027, 2007.

Furuichi, N., Hibiya, T., and Niwa, Y.: Model-predicted distribution of wind-induced internal wave energy in the world's oceans, J. Geophys. Res.-Oceans, 113, C09034, doi:10.1029/2008JC004768, 2008.

Garrett, C.: What is the "near-inertial" band and why is it different from the rest of the internal wave spectrum?, J. Phys. Oceanogr., 31, 962-971, 2001.

Gill, A. E.: On the Behavior of Internal Waves in the Wakes of Storms, J. Phys. Oceanogr., 14, 1129-1151, 1984.

Hu, J. Y., Kawamura, H., Hong, H. S., and Qi, Y.: A review on the currents in the South China Sea: Seasonal circulation, South China Sea Warm Current and Kuroshio intrusion, J. Oceanogr., 56, 607-624, 2000.

Isobe, A. and Namba, T.: The circulation in the upper and intermediate layers of the South China Sea, J. Oceanogr., 57, 93-104, 2001.

Komori, N., Ohfuchi,W., Taguchi, B., Sasaki, H., and Klein, P.: Deep ocean inertia-gravity waves simulated in a high-resolution global coupled atmosphere-ocean GCM, Geophys. Res. Lett., 35, L04610, doi:10.1029/2007GL032807, 2008.

Kunze, E.: Near-inertial wave propagation in geostrophic shear, J. Phys. Oceanogr., 15, 544-565, 1985.

Lan, J., Zhang, N., and Wang, Y.: On the dynamics of the South China Sea deep circulation, J.Geophys. Res.-Oceans, 118, 12061210, 2013.

Lan, J., Wang, Y., Cui, F., and Zhang, N.: Seasonal variation in the South China Sea deep circulation, J. Geophys. Res.-Oceans, 120, 1682-1690, 2015.

Lee, D. K. and Niiler, P. P.: The inertial chimney: The near-inertial energy drainage from the ocean surface to the deep layer, J. Geophys. Res.-Oceans, 103, 7579-7591, 1998.

Liang, X. F., Zhang, X. Q., and Tian, J. W.: Observation of internal tides and near-inertial motions in the upper $450 \mathrm{~m}$ layer of the northern South China Sea, Chin. Sci. Bull., 50, 2890-2895, 2005.

Li, J., Liu, J., Cai, S., and Pan, J.: The spatiotemporal variation of the wind-induced near-inertial energy flux in the mixed layer of the South China Sea, Acta Oceanol. Sin., 34, 66-72, 2015.

Li, L. and Qu, T.: Thermohaline circulation in the deep South China Sea basin inferred from oxygen distributions, J. Geophys. Res.Oceans, 111, C05017, doi:10.1029/2005JC003164,2006.
Liu, C., Du, Y., Zhang, Q., and Wang, D.: Seasonal variation of subsurface and intermediate water masses in the South China Sea, Oceanol. Limnol. Sin., 39, 55-64, 2008.

Liu, C., Wang, D., Chen, J., Du, Y., and Xie, Q.: Freshening of the intermediate water of the South China Sea between the 1960s and the 1980s, Chin. J. Oceanol. Limn., 30, 1010-1015, 2012.

Liu, Z., Yang, H., and Liu, Q.: Regional Dynamics of Seasonal Variability in the South China Sea. J. Phys. Oceanogr., 31, 272-284, 2001.

Munk, W. and Wunsch, C.: Abyssal recipes II, Energetics of tidal and wind mixing, Deep-Sea Res. Pt. I, 45, 1977-2010, 1998.

Nagai, T., Tandon, A., Kunze, E., and Mahadevan, A.:Spontaneous Generation of Near-Inertial Waves by the Kuroshio Front, J. Phys. Oceanogr., 45, 2381-2406, 2015.

Nan, F., Xue, H., and Yu, F.: Kuroshio intrusion into the South China Sea: A review, Prog. Oceanogr., 137, 314-333, doi:10.1016/j.pocean.2014.05.012, 2014.

Qu, T. D.: Upper-layer circulation in the South China Sea, J. Phys. Oceanogr., 30, 1450-1460, 2000.

Qu, T., Kim, Y. Y., Yaremchuk, M., Tozuka, T., Ishida, A., and Yamagata, T.: Can Luzon Strait transport play a role in conveying the impact of ENSO to the South China Sea?, J. Climate, 17, 3644-3657, 2004.

Qu, T., Du, Y., Meyers, G., Ishida, A., and Wang, D.: Connecting the tropical Pacific with Indian Ocean through South China Sea, Geophys. Res. Lett., 32, L24609, doi:10.1029/2005GL024698, 2005.

Qu, T., Girton, J. B., and Whitehead, J. A.: Deepwater overflow through Luzon strait, J. Geophys. Res.-Oceans, 111, C01002, doi:10.1029/2005JC003139, 2006.

Rimac, A., von Storch, J.-S., Eden, C., and Haak, H.: The influence of high-resolution wind stress field on the power input to nearinertial motions in the ocean, Geophys. Res. Lett., 40, 48824886, doi:10.1002/grl.50929, 2013.

Sévellec, F., Hirschi, J. J. M., and Blaker, A. T.: On the Near-Inertial Resonance of the Atlantic Meridional Overturning Circulation, J. Phys. Oceanogr., 43, 2661-2672, 2013.

Shu, Y., Xue, H., Wang, D., Chai, F., Xie, Q., Yao, J., and Xiao, J.: Meridional overturning circulation in the South China Sea envisioned from the high-resolution global reanalysis data GLBa 0.08, J. Geophys. Res.-Oceans, 119, 3012-3028, 2014.

$\mathrm{Su}$, J.: Overview of the South China Sea circulation and its influence on the coastal physical oceanography outside the Pearl River Estuary, Cont. Shelf Res., 24, 1745-1760, 2004.

Thoppil, P. G., Richman, J. G., and Hogan, P. J.: Energetics of a global ocean circulation model compared to observations, Geophys. Res. Lett., 38, L15607, doi:10.1029/2011GL048347,2011.

Tian, J., Yang, Q., Liang, X., Xie, L., Hu, D., Wang, F., and Qu, T. Observation of Luzon Strait transport, Geophys. Res. Lett., 33, L19607, doi:10.1029/2006GL026272, 2006.

Tian, J., Yang, Q., and Zhao, W.: Enhanced diapycnal mixing in the South China Sea, J. Phys. Oceanogr., 39, 3191-3203, 2009.

von Storch, J.-S.: Variations of vertical velocity in the deep oceans simulated by a $1 / 10^{\circ}$ OGCM, Ocean Dynam., 60, 759-770, 2010.

Wang, D., Liu, Y., Qi, Y., and Shi, P.: Seasonal variability of thermal fronts in the northern South China Sea from satellite data, Geophys. Res. Lett., 28, 3963-3966, 2001. 
Wang, D., Liu, X., Wang, W., Du, Y., and Zhou, W.: Simulation of meridional overturning in the upper layer of the South China Sea with an idealized bottom topography, Chin. Sci. Bull., 49, 740-747, 2004.

Wang, D., Liu, Q., Huang, R. X., Du, Y., and Qu, T.: Interannual variability of the South China Sea throughflow inferred from wind data and an ocean data assimilation product, Geophys. Res. Lett., 33, L14605, doi:10.1029/2006GL026316, 2006.

Wang, G., Su, J., Ding, Y., and Chen, D.: Tropical cyclone genesis over the south China sea, J. Mar. Syst., 68, 318-326, 2007.

Wang, G., Xie, S. P., Qu, T., and Huang, R. X.: Deep South China Sea circulation, Geophys. Res. Lett., 38, L05601, doi:10.1029/2010GL046626, 2011.

Wang, S., Zhang, F., and Snyder, C.: Generation and propagation of inertia-gravity waves from vortex dipoles and jets, J. Atmos. Sci, 66, 1294-1314, 2009.

Wang, W., Wang, D., Shi, P., Guo, P., and Gan Z.: Establishment and adjustment of monsoon-driven circulation in the South China Sea, Sci. China Ser. D, 46, 173-181, 2003.

Wang, Y., Fang, G., Wei, Z., Qiao, F., and Chen, H.: Interannual variation of the South China Sea circulation and its relation to El Niño, as seen from a variable grid global ocean model, J. Geophys. Res.-Oceans, 111, C11S14, doi:10.1029/2005JC003269, 2006.

Whitt, D. B. and Thomas, L. N.: Near-inertial waves in strongly baroclinic currents, J. Phys. Oceanogr., 43, 706-725, 2013.

Wyrtki, K.: Physical oceanography of the southeast Asian waters: Scientific results of marine investigations of the South China Sea and the Gulf of Thailand 1959-1961, NAGA Rep. 2, 195 pp., Scripps Inst. Oceanogr., La Jolla, CA, USA, 1961.

Xie, Q., Xiao, J., Wang, D., and Yu, Y.: Analysis of deep-layer and bottom circulations in the South China Sea based on eight quasiglobal ocean model outputs, Chin. Sci. Bull., 58, 4000-4011, 2013.

Xie, X.-H., Shang, X.-D., Chen, G.-Y., and Sun, L.: Variations of diurnal and inertial spectral peaks near the bidiurnal critical latitude, Geophys. Res. Lett., 36, L02606, doi:10.1029/2008GL036383, 2009.

Xu, F. H. and Oey, L. Y.: State analysis using the Local Ensemble Transform Kalman Filter (LETKF) and the three-layer circulation structure of the Luzon Strait and the South China Sea, Ocean. Dynam., 64, 905-923, 2014.
Xu, Z., Yin, B., Hou, Y., and Xu, Y.: Variability of internal tides and near-inertial waves on the continental slope of the northwestern South China Sea, J. Geophys. Res.-Oceans, 118, 197-211, doi:10.1029/2012JC008212, 2013.

Yang, J. and Price, J. F.: Water mass formation and potential vorticity balance in an abyssal ocean circulation model, J. Mar. Res., 58, 789-808, 2000.

Yang, J. and Price, J. F.: Potential vorticity constraint on the flow between two basins, J. Phys. Oceanogr., 37, 2251-2266, 2007.

Yang, Q., Tian, J., and Zhao, W.: Observation of Luzon Strait transport in summer 2007, Deep-Sea Res. Pt. I, 57, 670-676, 2010.

Yang, Q., Zhou, L., Tian, J., and Zhao,W.: The Roles of Kuroshio Intrusion and Mesoscale Eddy in Upper Mixing in the Northern South China Sea, J. Coastal Res., 30, 192-198, 2013.

Yang, Q., Tian, J., Zhao, W., Liang, X., and Zhou, L.: Observations of turbulence on the shelf and slope of northern South China Sea, Deep-Sea Res. Pt. I, 87, 43-52, 2014.

Yuan, D.: A numerical study of the South China Sea deep circulation and its relation to the Luzon Strait transport, Acta Oceanol. Sin., 21, 187-202, 2002.

Yuan, Y. C., Zhao, J. P., Wang, H. Q., Lou, R. Y., Chen, H., and Wang, K. S.: The observation and spectral analysis of currents above 450 and in the deep depth of the northeastern South China Sea, Sci. China Earth Sci., 32, 163-176, 2002.

Zhai, X., Greatbatch, R. J., and Zhao, J.: Enhanced vertical propagation of storm-induced near-inertial energy in an eddying ocean channel model, Geophys. Res. Lett., 32, L18602, doi:10.1029/2005GL023643, 2005.

Zhang, N., Lan, J., and Cui, F.: The shallow meridional overturning circulation of the South China Sea, Ocean Sci. Discuss., 11, 1191-1212, doi:10.5194/osd-11-1191-2014, 2014.

Zheng, L., Wang, G., and Wang, C.: Out-of-phase relationship between tropical cyclones generated locally in the South China Sea and non-locally from the Northwest Pacific Ocean, Clim. Dynam., 45, 1129-1136, 2015. 